\title{
Association between household food access insecurity and nutritional status indicators among children aged $<5$ years in Nepal: results from a national, cross-sectional household survey
}

\author{
Chandrashekhar T Sreeramareddy ${ }^{1, *}$, N Ramakrishnareddy ${ }^{2}$ and Mayoori Subramaniam ${ }^{3}$ \\ 'Department of Population Medicine, Faculty of Medicine and Health Sciences, Universiti Tunku Abdul Rahman, \\ Jalan Sungai Long, Bandar Sungai Long, Post code: 43000, Kajang, Cheras, Selangor, Malaysia: ${ }^{2}$ Department of \\ Community Medicine, Bangalore Medical College and Research Institute, Bangalore, Karnataka, India: ${ }^{3}$ Faculty of \\ Medicine and Health Sciences, Universiti Tunku Abdul Rahman, Bandar Sungai Long, Selangor, Malaysia
}

Submitted 2 December 2013: Final revision received 8 0ctober 2014: Accepted 20 October 2014: First published online 1 December 2014

\begin{abstract}
Objective: To examine the association between household food insecurity score and $Z$-scores of childhood nutritional status indicators.

Design: Population-based, cross-sectional survey, Nepal Demographic and Health Survey 2011.

Setting: A nationally representative sample of 11085 households selected by a two-stage, stratified cluster sampling design to interview eligible men and women. Subjects: Children ( $n$ 2591) aged 0-60 months in a sub-sample of households selected for men's interview.

Results: Prevalence of moderate and severe household food insecurity was $23.2 \%$ and $19.0 \%$, respectively, for children aged 0-60 months. Weighted prevalence rates for stunting (height-for-age $Z$-score $(\mathrm{HAZ})<-2$ ), wasting (weight-for-height $Z$-score (WHZ) <-2) and underweight (weight-for-age $Z$-score (WAZ) $<-2$ ) were $41.6 \%$ (95\% CI 38.9, 44.3\%), 11.5\% (95\% CI 9.8, 13.2\%) and 30.1\% (95\% CI 27.5, $32.8 \%)$, respectively. Prevalences of stunting, severe stunting $(\mathrm{HAZ}<-3)$ and underweight by level of household food insecurity were statistically significant $(P<0 \cdot 001)$. By multiple linear regression analyses and after adjustment for sociodemographic, child and environmental factors, household food access insecurity score was associated with $\operatorname{HAZ}(\beta=-0.02, P=0.01)$ and WAZ $(\beta=-0 \cdot 01, P=0 \cdot 01)$ but was not associated with WHZ and BMI-for-age $Z$-score. A 10-point increase in household food access insecurity score was associated with a decrease in HAZ of $0.2(95 \%$ CI $0.05,0.39)$ and decrease in WAZ of 0.1 (95\% CI $0 \cdot 03,0 \cdot 27$ ).

Conclusions: Our results from a nationally representative sample confirm the previously reported association of household food insecurity with stunting and underweight. Community nutrition interventions may use household food insecurity scales for identifying those households where children may be at risk of growth faltering.
\end{abstract}

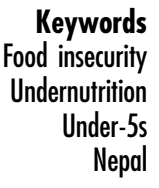

Worldwide more than 300 million children aged less than 5 years are chronically undernourished ${ }^{(1)}$ and one-fifth of all children in developing countries are undernourished ${ }^{(2)}$. Undernutrition accounts for $3.4 \%$ of the total global burden of disease ${ }^{(3)}$ and contributes to about half of the child deaths occurring worldwide ${ }^{(4)}$. Therefore, improvement of nutritional status by implementing appropriate policies and interventions is a priority for the achievement of Millennium Development Goal $4^{(5)}$. Household food insecurity (HFI), proposed to be one of the causes for childhood undernutrition, is prevalent worldwide, particularly in developing countries ${ }^{(1,6)}$. Food insecurity is defined as limited or uncertain availability of nutritionally adequate and safe foods or limited or uncertain ability to acquire acceptable foods in socially acceptable ways ${ }^{\text {,(7) }}$. According to the World Food Summit 1996, food security occurs 'when all people at all times have access to sufficient, safe, nutritious food to maintain a healthy and active life, (8).

Studies from a few developing countries have reported that HFI is associated with childhood undernutrition indicators such as stunting and underweight ${ }^{(9-15)}$, but a study from Brazil has reported that HFI was not associated with 
$Z$-score for BMI-for-age or weight-for-height ${ }^{(16)}$. These studies were done among schoolchildren and pre-school children in Columbia ${ }^{(11,12)}$, tribal children aged 6-59 months in West Bengal, India ${ }^{(13)}$, children aged 6-18 months living in urban squatter settlements of Karachi, Pakistan ${ }^{(10)}$ and a nationally representative sample of children aged 0-60 months in Brazil ${ }^{(16)}$. A multinational study from eight countries was done on a sample of 100 children aged 24-60 months in each country ${ }^{(14)}$ and another study included samples ranging from 2356 to 3422 children aged 6-60 months in three countries $^{(9)}$, but none covered a nationally representative sample of children aged $<5$ years. In most of the studies, the association of HFI with stunting and underweight was consistent despite different instruments being applied to measure $\mathrm{HFI}^{(9-15)}$. However, using level of HFI and/or stunting, wasting, etc. in multivariate analyses in most studies ${ }^{(9-12,16)}$ may have led to loss of power and/or residual confounding for the association between HFI and undernutrition.

Childhood undernutrition is an important public health problem in South Asian countries ${ }^{(17)}$. Among them Nepal too has a high prevalence of childhood undernutrition alongside widespread poverty ${ }^{(17)}$. Prevalence rates of stunting, underweight and wasting are still high at $41 \%$, $29 \%$ and $11 \%$, respectively, despite a reduction over the last two decades ${ }^{(18)}$. HFI is also prevalent in $\mathrm{Nepal}^{(19)}$, where forty-two of the seventy-five districts are considered as food deficient ${ }^{(20)}$ and about $40 \%$ of the Nepalese population lives on less than \$US 1 per day ${ }^{(21)}$. A study from Kailali District has reported that two-thirds of the surveyed households reported some degree of food insecurity but HFI was not associated with stunting and wasting among children aged 6-23 months ${ }^{(22)}$. However, a national-level report on the association of HFI with childhood undernutrition has not been published. The Nepal Demographic and Health Survey 2011 (NDHS 2011) collected information about child anthropometry and the HFI situation over a 12-month period. We did a secondary data analysis of NDHS 2011 to further examine the association between HFI score and $Z$-scores of four child anthropometric indicators.

\section{Methods}

\section{Etbics statement}

The standard survey protocols, questionnaires and procedures of anthropometry for NDHS 2011 were reviewed and approved by the Independent Review Boards of New ERA (a non-governmental organization) and ORC (Opinion Research Corporation) Macro International Inc. (Calverton, MD, USA). Eligible persons of the households were informed that participation was voluntary and were assured about confidentiality of the information they would provide during the interview. Participants were told that they could refrain from responding to any of the questions. Prior to the interview, informed consent was obtained from each participant. Written consent was not necessary since participants were not subjected to any type of intervention. However, interviewers recorded consent in the questionnaire and signed the consent form. The Independent Review Board of both ORC Macro International Inc. and New ERA had approved this consent procedure.

\section{Data source}

Data for the present analysis were obtained with written permission from ORC Macro International Inc. for the fourth round of NDHS 2011 done under the administrative supervision of the Ministry of Health and Population and implemented by New ERA, a local research organization (http://www.newera.com.np/). NDHS 2011 was technically supported by ORC Macro International Inc. and funded by the US Agency for International Development.

\section{Study design, sampling and sample size}

NDHS 2011 was a population-based, cross-sectional study on a nationally representative sample of households. The survey sampling design was based on an updated sampling frame of the 2001 Census where enumeration areas were listed for sampling. A two-stage, stratified cluster sampling design was followed after stratification of enumeration areas as urban and rural. At the first stage, enumeration areas were selected by the probabilityproportional-to-size technique and in the second stage, a minimum of 600 households was selected in each selected enumeration area. To obtain an acceptable level of precision for important population characteristics such as infant mortality, fertility, prevalence of contraceptives use, etc., a sample of 11085 households was selected to completely interview a total of 13485 women. Overall, a total of 12674 women and 4121 men were interviewed; the response rates for women and men were $97.6 \%$ and $94.7 \%$, respectively.

\section{Antbropometric indicators}

Height and weight were measured for all children born during the five years preceding the survey date in a subsample of households selected for interviewing male respondents. For all eligible children (aged 0-60 months) weight and height or length were measured by methods recommended by the $\mathrm{WHO}^{(23)}$. Weight was measured using a lightweight SECA scale having a digital monitor designed and monitored by UNICEF (SECA Medical Scales and Measuring Systems, Birmingham, UK). Weight was measured to a precision of $100 \mathrm{~g}$ and the scale was calibrated at the beginning and the end of each working day. Height or length was measured using specially designed measuring boards (stadiometers; Shorr Productions LLC, Olney, MD, USA). Height or length was measured to a precision of $1 \mathrm{~mm}$ and stadiometers were also calibrated at the beginning and the end of each working day. Children aged less 
than 2 years or shorter than $85 \mathrm{~cm}$ were measured in a lying down position (length). Two readings of weight and height/length were taken and the average reading was recorded. Height-for-age $Z$-scores (HAZ), weight-for-age $Z$-scores (WAZ), weight-for-height $Z$-scores (WHZ) and BMI-for-age $Z$-scores (BMIZ) were computed as per new 2006 WHO child growth standards based on the Multicentre Growth Reference Study ${ }^{(24)}$.

\section{Housebold food insecurity}

In NDHS 2011, HFI was measured using the Household Food Insecurity Access Scale (HFIAS) developed for the Food and Nutrition Technical Assistance project of the US Agency for International Development. The HFIAS measures household access to food, which is one of the three components of food insecurity: i.e. availability, access and utilization $^{(25)}$. HFIAS has been shown to be a low-cost, valid tool that can be applied to estimate the prevalence of household food insecurity ${ }^{(26)}$ and be used in different settings ${ }^{(14)}$. To suit the Nepalese context, NDHS 2011 used a modified HFIAS that included seven of the nine generic questions with a recall period of 12 months instead of $30 \mathrm{~d}$ in the original HFIAS. In NDHS 2011, HFIAS was administered to the head of the household to assess the 'food security' situation in the house. Response options for each question were on a Likert scale of 'never', 'rarely', 'sometimes' and 'often', coded as 0, 1, 2 and 3, respectively. The food insecurity score, generated by summing up the responses to the seven questions, had a range from 0 (most food access secure) to 21 (most food access insecure). Further, each household was categorized as food secure, mild, moderate or severe food insecurity based on the responses provided to increasingly severe conditions and the frequency of experiencing such con- ditions during the previous 12 months as described by the HFIAS manual ${ }^{(25)}$.

\section{Covariates}

During NDHS 2011, demographic, socio-economic and health information was collected by interviewing all eligible men and women during the household survey. To assess the potential confounding effect of various determinants of undernutrition, we used UNICEF's conceptual framework for childhood undernutrition (Fig. 1) ${ }^{(27)}$. The independent variables included in the analyses were age (in months), sex and birth order of the child, history of childhood illness during the previous two weeks, mother's highest education, having a bank account, household sanitation characteristics (type of toilet, source of drinking water, and if anything was done to make the water safe for drinking), total number of household members, indoor air pollution indicators (namely, indoor smoking; any household members smoke inside the house) and the type of fuel used for cooking.

\section{Statistical analysis}

We performed descriptive analyses for HFIAS questions, level of HFI, HFIAS score, HAZ, WAZ, WHZ and BMIZ. Weighted prevalence rates for stunting, wasting and underweight were calculated for each category level of HFI. Level of HFI was compared according to household wealth index, total number of household members, age, sex and birth order of the child, and spatial variables. HAZ, WAZ, WHZ and BMIZ were compared by the level of HFI. The $\chi^{2}$ test and ANOVA were done to test the statistical significance of differences in proportions and means, respectively. Instead of categorical variables such as level of HFI, stunting, wasting and underweight, we used HFIAS score, HAZ, WAZ, WHZ and BMIZ as continuous variables

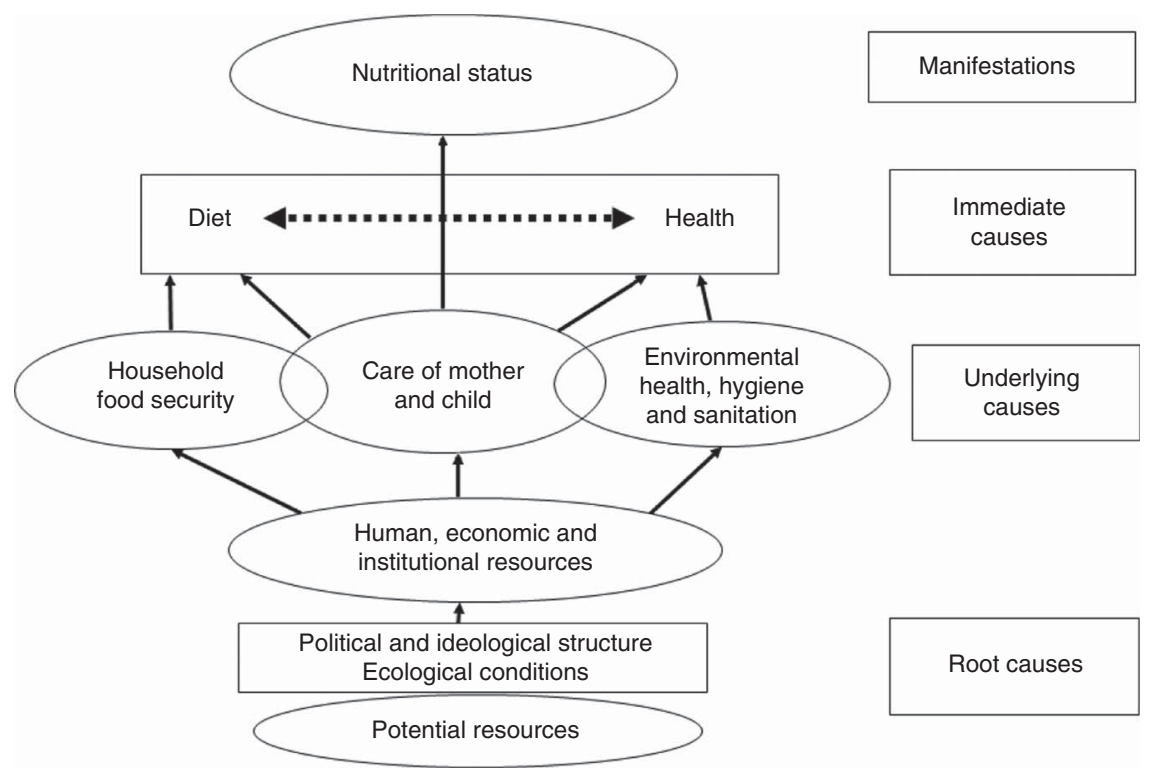

Fig. 1 UNICEF's conceptual framework of malnutrition 
to test the association between HFI and nutritional status indicators. Univariate analyses followed by multiple linear regression analyses were done. Regression models for each of the four nutritional status indicators (Z-scores) were adjusted for all hypothesized confounding factors such as child's age, sex and birth order, mother's education, smoking indoors, having a bank account, type of drinking water source, type of toilet, type of cooking fuel used and total number of household members as per UNICEF's conceptual framework for childhood undernutrition. The associations were considered significant if the $P$ value was $<0 \cdot 05$. After the full model, only factors that were significant $(P<0.05)$ were included in the final model. All of the regression analysis models were adjusted for the complex sampling design of NDHS 2011 by including a household weighting factor using the 'svyset' command in the statistical software package Stata/IC 10·1.

\section{Results}

A total of 10826 household heads were interviewed with the HFIAS questionnaire. The most common conditions of HFI reported as occurring 'often' during the previous 12 months were 'worry about not having enough food' (18.9\%), 'not able to eat preferred foods' (13.7\%) and 'eating a limited variety' (12.0\%). For 2591 children aged $<5$ years included in the final analysis, the mean and median HFIAS scores were 3.79 and 1 , respectively (Table 1 ). Nearly half of the households were food secure, but $23.2 \%$ of them had moderate HFI and $19.0 \%$ had severe HFI.

Anthropometric measurements, height and weight were done for 2591 children. Significantly higher proportions of children from mid-western and far-western regions $(P<0.001)$, mountains and hilly zones $(P<0.001)$ and rural areas $(P<0 \cdot 001)$ lived in households with moderate to severe HFI, compared with mild HFI. Similarly, significantly higher proportions of children from poorest and poorer households $(P<0.001)$ and born of higher birth order $(P<0.001)$ were in the households having moderate to severe HFI, compared with mild HFI (Table 2).

Weighted prevalence rates for stunting $(\mathrm{HAZ}<-2)$, wasting (WHZ $<-2$ ) and underweight (WAZ $<-2$ ) were
$41.63 \%, 11.51 \%$ and $30.12 \%$, respectively; while weighted prevalence rates for severe stunting ( $\mathrm{HAZ}<-3)$, severe wasting (WHZ $<-3)$ and severe underweight (WAZ $<-3$ ) were $16.35 \%, 2.76 \%$ and $8.07 \%$, respectively. The differences in prevalence of stunting and severe stunting, etc. according to HFI level were statistically significant for stunting $(P<0.001)$, severe stunting $(P=0.001)$ and underweight $(P<0.001)$ only (Table 3$)$, whereas the differences in mean values of HAZ, WAZ, WHZ and BMIZ according to HFI level were all statistically significant $(P<0 \cdot 01 ;$ Table 4$)$

In multiple linear regression analyses, HFIAS score was associated with HAZ $(P=0.04)$ and WAZ $(P=0.04)$ in the full models and also in the final models after adjusting for covariates, but HFIAS score was not associated with WHZ or BMIZ in either model (Table 5). A 10-point increase in HFIAS score was associated with a decrease in HAZ of $0.2(95 \%$ CI $0.05,0.39)$ and a decrease in WAZ of $0.1 \quad(95 \%$ CI $0.03,0.27)$. Mother's education and child's age were associated with HAZ, WAZ and WHZ. Other covariates associated with nutritional indicators were child's birth order and having a bank account (with HAZ and WAZ); and type of toilet, making drinking water safe and source of drinking water (with WHZ and BMIZ; Table 5).

\section{Discussion}

Nearly half of the households in Nepal experienced some degree of HFI and the prevalence of stunting and underweight among children aged $<5$ years living in food-insecure households was higher than among children in food-secure households. After adjusting for child, mother and household factors, HFIAS score was associated with stunting and underweight but not with wasting and BMI. An increase in HFIAS score was significantly associated with decreased HAZ and WAZ, which correspond to an increased risk of stunting and underweight, respectively.

Prevalence of HFI in Nepal was similar to that in Antioquia, Columbia ${ }^{(11)}$ and Brazil ${ }^{(16)}$ but lower than in Bogota, Columbia ${ }^{(12)}$. However, the scales used to measure HFI were diverse in these studies and also in others

Table 1 Conditions related to household food access during the 12 months prior to the interview date, Nepal Demographic and Health Survey 2011 (10 826 households)

\begin{tabular}{|c|c|c|c|c|}
\hline Question & Never (\%) & Rarely (\%) & Sometimes (\%) & Often $(\%$ \\
\hline 1. Worried that your household would not have enough food in the past 12 months & 53.7 & $7 \cdot 3$ & $20 \cdot 0$ & 18.9 \\
\hline 2. Not able to eat preferred foods because of lack of resources in the past 12 months & $55 \cdot 7$ & $9 \cdot 8$ & $20 \cdot 8$ & 13.7 \\
\hline 3. Ate a limited variety due to lack of resources in the past 12 months & $57 \cdot 1$ & $10 \cdot 7$ & $20 \cdot 2$ & $12 \cdot 0$ \\
\hline 4. Ate smaller meals because there was not enough food in the past 12 months & 78.4 & 9.4 & 9.9 & $2 \cdot 3$ \\
\hline 5. Ate fewer meals in a day because of lack of resources in the past 12 months & 83.8 & 7.9 & $6 \cdot 8$ & 1.4 \\
\hline 6. No food to eat because of lack of resources in the past 12 months & $86 \cdot 7$ & $7 \cdot 1$ & $5 \cdot 3$ & 1.0 \\
\hline 7. Went to sleep hungry because there was not enough food in the past 12 months & 91.5 & 4.9 & 3.0 & 0.6 \\
\hline
\end{tabular}

Overall HFIAS (Household Food Insecurity Access Scale) score: mean=3.79 (SD 4.83); median=1 (interquartile range 1-7). 
Table 2 Distribution of HFI level according to sociodemographic and child factors, Nepal Demographic and Health Survey 2011 (10 826 households)

\begin{tabular}{|c|c|c|c|c|c|c|c|c|c|}
\hline & & & \multicolumn{6}{|c|}{ Level of HFI } & \multirow[b]{3}{*}{$P$ value } \\
\hline & \multicolumn{2}{|c|}{ Food secure } & \multicolumn{2}{|c|}{ Mild } & \multicolumn{2}{|c|}{ Moderate } & \multicolumn{2}{|c|}{ Severe } & \\
\hline & $n$ & $\%$ & $n$ & $\%$ & $n$ & $\%$ & $n$ & $\%$ & \\
\hline Total & 1079 & 41.6 & 419 & $16 \cdot 2$ & 602 & 23.2 & 491 & $19 \cdot 0$ & \\
\hline \multicolumn{10}{|l|}{ Wealth index } \\
\hline Poorest & 95 & $12 \cdot 2$ & 159 & $20 \cdot 4$ & 291 & 37.4 & 234 & $30 \cdot 0$ & $<0.001$ \\
\hline Poorer & 161 & 30.7 & 100 & $19 \cdot 0$ & 144 & $27 \cdot 4$ & 120 & 22.9 & \\
\hline Middle & 233 & 47.7 & 72 & $14 \cdot 8$ & 90 & 18.4 & 93 & $19 \cdot 1$ & \\
\hline Richer & 258 & $65 \cdot 2$ & 55 & 13.9 & 49 & $12 \cdot 4$ & 34 & $8 \cdot 6$ & \\
\hline Richest & 332 & $82 \cdot 4$ & 33 & $8 \cdot 2$ & 28 & $6 \cdot 9$ & 10 & 2.5 & \\
\hline \multicolumn{10}{|c|}{ Members in the household } \\
\hline$\leq 5$ members & 530 & 43.9 & 193 & $16 \cdot 0$ & 279 & 23.1 & 205 & $17 \cdot 0$ & 0.059 \\
\hline$>5$ members & 549 & 39.7 & 226 & $16 \cdot 3$ & 323 & $23 \cdot 3$ & 286 & $20 \cdot 7$ & \\
\hline \multicolumn{10}{|c|}{ Development region } \\
\hline Eastern & 317 & $52 \cdot 3$ & 101 & $16 \cdot 7$ & 103 & $17 \cdot 0$ & 85 & $14 \cdot 0$ & $<0.001$ \\
\hline Central & 290 & 52.0 & 78 & $14 \cdot 0$ & 117 & 21.0 & 73 & $13 \cdot 1$ & \\
\hline Western & 189 & $48 \cdot 6$ & 47 & $12 \cdot 1$ & 80 & $20 \cdot 6$ & 73 & $18 \cdot 8$ & \\
\hline Mid-western & 141 & $24 \cdot 4$ & 96 & $16 \cdot 6$ & 142 & $24 \cdot 6$ & 198 & $34 \cdot 3$ & \\
\hline Far-western & 142 & 30.8 & 97 & $21 \cdot 0$ & 160 & 34.7 & 62 & 13.4 & \\
\hline \multicolumn{10}{|l|}{ Ecological zone } \\
\hline Mountain & 163 & $34 \cdot 0$ & 124 & $25 \cdot 8$ & 120 & $25 \cdot 0$ & 73 & $15 \cdot 2$ & $<0.001$ \\
\hline Hill & 373 & 35.5 & 164 & $15 \cdot 6$ & 337 & $32 \cdot 1$ & 177 & $16 \cdot 8$ & \\
\hline Terai & 543 & 51.2 & 131 & 12.4 & 145 & 13.7 & 241 & $22 \cdot 7$ & \\
\hline \multicolumn{10}{|c|}{ Type of place of residence } \\
\hline Urban & 322 & 58.2 & 69 & 12.5 & 73 & 13.2 & 89 & $16 \cdot 1$ & $<0.001$ \\
\hline Rural & 757 & $37 \cdot 1$ & 350 & $17 \cdot 2$ & 529 & $26 \cdot 0$ & 402 & $19 \cdot 7$ & \\
\hline \multicolumn{10}{|c|}{ Mother's highest education level } \\
\hline No education & 283 & 24.5 & 203 & $17 \cdot 6$ & 333 & 28.8 & 336 & $29 \cdot 1$ & 0.06 \\
\hline Primary & 201 & $40 \cdot 3$ & 94 & $18 \cdot 8$ & 126 & $25 \cdot 3$ & 78 & $15 \cdot 6$ & \\
\hline Secondary & 440 & 61.5 & 97 & 13.6 & 115 & $16 \cdot 1$ & 63 & 8.8 & \\
\hline Higher & 128 & 82.1 & 11 & $7 \cdot 1$ & 15 & $9 \cdot 6$ & 2 & 1.3 & \\
\hline \multicolumn{10}{|l|}{ Sex of the child } \\
\hline Male & 544 & 40.7 & 223 & $16 \cdot 7$ & 321 & $24 \cdot 0$ & 250 & $18 \cdot 7$ & 0.60 \\
\hline Female & 535 & $42 \cdot 7$ & 196 & $15 \cdot 6$ & 281 & 22.4 & 241 & $19 \cdot 2$ & \\
\hline \multicolumn{10}{|l|}{ Child's age } \\
\hline$\leq 24$ months & 428 & $42 \cdot 3$ & 149 & $14 \cdot 7$ & 247 & $24 \cdot 4$ & 188 & 18.6 & 0.33 \\
\hline$>24$ months & 651 & 41.2 & 270 & $17 \cdot 1$ & 355 & 22.5 & 303 & $19 \cdot 2$ & \\
\hline \multicolumn{10}{|c|}{ Birth order of the child } \\
\hline 1 & 394 & $52 \cdot 7$ & 112 & $15 \cdot 0$ & 146 & 19.5 & 96 & $12 \cdot 8$ & $<0.001$ \\
\hline 2 & 268 & $44 \cdot 0$ & 100 & $16 \cdot 4$ & 145 & 23.8 & 96 & $15 \cdot 8$ & \\
\hline$\geq 3$ & 324 & 31.3 & 179 & $17 \cdot 3$ & 279 & $26 \cdot 9$ & 254 & 24.5 & \\
\hline
\end{tabular}

$\mathrm{HFI}$, household food insecurity.

from Bangladesh ${ }^{(15)}$, Pakistan ${ }^{(10)}$ and India ${ }^{(13)}$, rendering HFI data non-comparable. HFI prevalence in NDHS 2011 was less than in the study (69\%) from Kailali District, far-western Nepal, which used a five-item scale similar to HFIAS ${ }^{(22)}$. When comparing the studies that used the HFIAS, prevalence in Nepal was higher than in Bangladesh and Vietnam but lower than in Ethiopia ${ }^{(9)}$. However, these comparisons should be interpreted cautiously because NDHS 2011 used a modified HFIAS, while Ali et al. used the original HFIAS on samples of children aged 6-60 months who were not nationally representative. Prevalence of stunting, underweight and wasting in Nepal had reduced compared with previous surveys ${ }^{(18)}$ but stunting was higher than wasting in accordance with a report from a multicounty study in Nigeria ${ }^{(28)}$.

Our study found that HFIAS score was associated with HAZ and WAZ, consistent with results of studies among children aged $<5$ years in Bangladesh ${ }^{(15)}$, Antioquia,

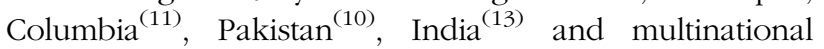
studies done in three ${ }^{(9)}$ and eight low- and middle-income countries $^{(14)}$, and also among schoolchildren (aged 5-12 years) in Bogota, Columbia ${ }^{(12)}$. However, our findings are contrary to the results of a study from Kailali District, $\mathrm{Nepal}^{(22)}$. The reason for the lack of association in the study from Kailali District could be the use of a different HFI scale among children aged 6-24 months, while stunting is a chronic condition common among children aged 3-5 years and caused by prolonged (chronic) hunger or food deprivation. Our study found no association between HFI and WHZ as in previous studies $^{(9,11,14,16,22)}$. There was no association between HFI and BMI in our study similar to a study from Brazil which did not test the association of HFI with HAZ and $\mathrm{WAZ}^{(16)}$. Contrary to our findings, HFI has been shown to 
Table 3 Distribution of weighted prevalence rates for stunting, underweight and wasting among children ( $n$ 2591) aged 0-60 months according to HFI level, Nepal Demographic and Health Survey 2011 (10826 households)

\begin{tabular}{|c|c|c|c|c|c|c|c|c|c|c|c|}
\hline & & & \multicolumn{8}{|c|}{ Level of HFI } & \multirow[b]{3}{*}{$P$ value } \\
\hline & \multicolumn{2}{|c|}{ Food secure } & \multicolumn{2}{|c|}{ Mild } & \multicolumn{2}{|c|}{ Moderate } & \multicolumn{2}{|c|}{ Severe } & \multicolumn{2}{|c|}{ Overall } & \\
\hline & $\%$ & $95 \% \mathrm{Cl}$ & $\%$ & $95 \% \mathrm{Cl}$ & $\%$ & $95 \% \mathrm{Cl}$ & $\%$ & $95 \% \mathrm{Cl}$ & $\%$ & $95 \% \mathrm{Cl}$ & \\
\hline Stunting ${ }^{*}$ & 34.60 & $30.28,38.92$ & $43 \cdot 25$ & $37 \cdot 33,49 \cdot 16$ & $46 \cdot 41$ & $41.23,51.59$ & 50.92 & $44.88,56.96$ & 41.63 & $38.97,44.30$ & $<0.001$ \\
\hline Severe stunting* & $12 \cdot 30$ & $9 \cdot 14,15.46$ & $15 \cdot 70$ & $11.31,19.43$ & $19 \cdot 27$ & $15.07,13.46$ & 22.90 & $17 \cdot 47,28 \cdot 34$ & $16 \cdot 35$ & $14 \cdot 31,18 \cdot 38$ & 0.0010 \\
\hline Wasting† & $10 \cdot 80$ & $8.40,13.19$ & $10 \cdot 21$ & $6.41,14.02$ & $13 \cdot 21$ & $9.48,16.94$ & $12 \cdot 11$ & $8 \cdot 62,15 \cdot 60$ & 11.51 & $9 \cdot 83,13 \cdot 19$ & 0.57 \\
\hline Severe wasting $\dagger$ & $2 \cdot 39$ & $1.28,3.49$ & 3.55 & $1.03,6.08$ & $3 \cdot 31$ & $1.84,4.78$ & $2 \cdot 33$ & $0.92,3.75$ & $2 \cdot 76$ & $2.04,3.47$ & 0.56 \\
\hline Underweight* & 24.02 & $19.61,28.43$ & $30 \cdot 23$ & $24 \cdot 24,34 \cdot 22$ & 33.68 & $29.56,37.81$ & 39.82 & $33.97,45.66$ & 30.12 & $27 \cdot 48,32 \cdot 76$ & $<0.001$ \\
\hline Severe underweight ${ }^{\star}$ & $6 \cdot 30$ & $4.14,8.56$ & 7.70 & $4.33,11 \cdot 15$ & 9.07 & $6.12,12.02$ & 11.08 & $7 \cdot 76,14.41$ & 8.07 & $6.53,9.61$ & 0.07 \\
\hline
\end{tabular}

$\mathrm{HFI}$, household food insecurity; $\mathrm{HAZ}$, height-for-age $Z$-score; WHZ, weight-for-height $Z$-score; WAZ, weight-for-age $Z$-score

Stunting, $H A Z<-2$; severe stunting, $H A Z<-3$; wasting, $W H Z<-2$; severe wasting, $W H Z<-3$; underweight, $W A Z<-2$; severe underweight, WAZ $<-3$.

2473 since data on HAZ and WAZ wore missing in 118 cases.

tTotal number of included cases was 2591 .

Table 4 Distribution of Z-scores of nutritional status indicators among children ( $n$ 2591) aged 0-60 months according to HFI level, Nepal Demographic and Health Survey 2011 (10 826 households)

\begin{tabular}{|c|c|c|c|c|c|c|c|c|c|c|c|c|}
\hline \multirow[b]{2}{*}{ Level of HFI } & \multicolumn{3}{|c|}{ HAZ } & \multicolumn{3}{|c|}{ WAZ } & \multicolumn{3}{|c|}{ WHZ } & \multicolumn{3}{|c|}{ BMIZ } \\
\hline & Mean & SD & $95 \% \mathrm{Cl}$ & Mean & SD & $95 \% \mathrm{Cl}$ & Mean & SD & $95 \% \mathrm{Cl}$ & Mean & SD & $95 \% \mathrm{Cl}$ \\
\hline $\begin{array}{l}\text { Food secure }(n 1014) \\
\text { Mild }(n 409) \\
\text { Moderate }(n 581) \\
\text { Severe }(n 469)\end{array}$ & $\begin{array}{l}-1.41 \\
-1.77 \\
-1.95 \\
-2.00\end{array}$ & $\begin{array}{l}1.37 \\
1.29 \\
1.36 \\
1.46 \\
P<C\end{array}$ & $\begin{array}{l}-1.49,1.32 \\
-1.90,1.65 \\
-2.06,1.84 \\
-1.76,1.65\end{array}$ & $\begin{array}{l}-1.20 \\
-1.46 \\
-1.67 \\
-1.74\end{array}$ & $\begin{array}{c}1.12 \\
1.04 \\
1.03 \\
1.14 \\
P<\end{array}$ & $\begin{array}{l}-1.27,1.13 \\
-1.56,-1.36 \\
-1.75,-1.58 \\
-1.84,-1.64 \\
1\end{array}$ & $\begin{array}{l}-0.56 \\
-0.61 \\
-0.77 \\
-0.82\end{array}$ & $\begin{array}{l}1.14 \\
1.06 \\
1.12 \\
1.10 \\
P<0\end{array}$ & $\begin{array}{l}-0.63,0.49 \\
-0.71,0.50 \\
-0.86,0.68 \\
-0.92,0.72\end{array}$ & $\begin{array}{l}-0.43 \\
-0.46 \\
-0.59 \\
-0.64\end{array}$ & $\begin{array}{l}1.14 \\
1.09 \\
1.16 \\
1.15 \\
P=C\end{array}$ & $\begin{array}{l}-0.50,0.36 \\
-0.50,-0.36 \\
-0.68,-0.50 \\
-0.74,-0.54 \\
2^{-}\end{array}$ \\
\hline
\end{tabular}

HFI, household food insecurity; HAZ, height-for-age Z-score; WAZ, weight-for-age Z-score; WHZ, weight-for-height Z-score; BMIZ, BMI-for-age Z-score. 
be associated with overweight (based on BMI) among adolescents and adults in both developed ${ }^{(29,30)}$ and developing countries ${ }^{(31-33)}$.

\section{Strengths and limitations}

One strength of our study was that we tested the hypothesis using data from a nationally representative sample of children aged $<5$ years and did robust statistical analyses using HFI, HAZ, WAZ and other variables as continuous data by linear regression and controlling for potential confounders according to UNICEF's conceptual framework. However, we did not use dietary intake in terms of quantity and quality since these questions in NDHS 2011 were asked for the $24 \mathrm{~h}$ prior to the survey whereas questions in the HFIAS were asked for the previous 12-month period. A previous study that tested children's dietary diversity did not find any association between dietary diversity and child undernutrition indicators $^{(9)}$. The same study also reported that HFI was associated with stunting and wasting, but the effect size decreased after the inclusion of wealth index ${ }^{(9)}$. The wealth index in NDHS 2011 was calculated based on various items related to environmental sanitation and hygiene that were also included in our regression models. Therefore to avoid possible collinearity of wealth index with factors such as type of fuel, source of water supply, etc., having a bank account was included as a proxy for wealth index in our regression models.

One potential limitation of our study was bias from a recall period of 12 months prior to the date of survey, whereas the original HFIAS recommends a $30 \mathrm{~d}$ recall period. As nearly $80 \%$ of the Nepalese population depends on subsistence farming, they usually face inadequate food supplies during the dry period between October and May. Therefore, a recall period of 12 months may have adjusted for the seasonal variations in the food supply while measuring HFI, as reported in previous studies $^{(9,14)}$. Reporting bias due to cultural stigma against food insecurity and use of a non-validated modified sevenitem version of HFIAS in NDHS 2011 may have resulted in lower estimates of HFI. Nevertheless, the HFIAS has good internal consistency (Cronbach's $\alpha=0.83-0.90)^{(34)}$, is known to distinguish households that are food secure from those that are food insecure across different cultural settings and has been used in several countries ${ }^{(24)}$. The association between HFIAS score and child undernutrition was assessed based on cross-sectional survey data in which HFI and child anthropometry were measured at the same time. Therefore, careful interpretations should be made about the association of HFI with stunting (WHZ) because stunting may have existed even before the household started experiencing food insecurity. Despite adopting UNICEF's conceptual framework, broader political and ecological conditions/contexts prevailing in Nepal could not be adjusted for in our analyses due to non-availability of their proxy measures. 


\section{Conclusion}

Our study confirms the previously reported association of HFI with stunting and underweight among children aged $<5$ years. However, the association between HFI and child undernutrition needs further verification in longitudinal studies to better understand the complex relationships between HFI, wealth index, and the quality and quantity of children's dietary intake. Notwithstanding, the HFIAS has potential use as a tool for detection of those households where children may be at risk of growth faltering and may be applicable in community-based nutritional interventions.

\section{Acknowledgements}

Acknowledgements: The authors thank ORC Macro International Inc. for providing access to the original data sets of the Nepal Demographic and Health Survey 2011 for conducting this analyses and preparing this manuscript. Financial support: This research received no specific grant from any funding agency in the public, commercial or notfor-profit sectors. Conflict of interest: None. Authorship: C.T.S. conceived and designed the study, analysed and interpreted the data and drafted the initial manuscript; N.R. helped in data analysis, interpretation of the data and corrected the initial drafts; M.S. helped in the data analysis, wrote the tables and results, and assisted in drafting the manuscript; all the authors were responsible for final editing and approval of the manuscript. Ethics of human subject participation: NDHS 2011 protocols, questionnaires and procedures were reviewed and approved by the Independent Review Boards of New ERA and ORC Macro International Inc.

\section{References}

1. Stevens GA, Finucane MM, Paciorek CJ et al. (2012) Trends in mild, moderate, and severe stunting and underweight, and progress towards MDG 1 in 141 developing countries: a systematic analysis of population representative data. Lancet 380, 824-834.

2. Black RE, Allen LH, Bhutta ZA et al. (2008) Maternal and child undernutrition: global and regional exposures and health consequences. Lancet 371, 243-260.

3. Murray CJ, Vos T, Lozano R et al. (2013) Disabilityadjusted life years (DALYs) for 291 diseases and injuries in 21 regions, 1990-2010: a systematic analysis for the Global Burden of Disease Study 2010. Lancet 380, 2197-2223.

4. Caulfield LE, de Onis M, Blossner M et al. (2004) Undernutrition as an underlying cause of child deaths associated with diarrhea, pneumonia, malaria, and measles. Am J Clin Nutr 80, 193-198.

5. Bhutta ZA, Ahmed T, Black RE et al. (2008) What works? Interventions for maternal and child undernutrition and survival. Lancet 371, 417-440.

6. Godfray HC, Beddington JR, Crute IR et al. (2010) Food security: the challenge of feeding 9 billion people. Science 327, 812-818.
7. Anderson SA (1990) Core indicators of nutritional state for difficult-to-sample populations. J Nutr 120, 1559-1600.

8. Maxwell S (1997) Implementing the World Food Summit Plan of Action: organisational issues in multi-sectoral planning. Food Policy 22, 515-531.

9. Ali D, Saha KK, Nguyen PH et al. (2013) Household food insecurity is associated with higher child undernutrition in Bangladesh, Ethiopia, and Vietnam, but the effect is not mediated by child dietary diversity. J Nutr $\mathbf{1 4 3}$, 2015-2021.

10. Baig-Ansari N, Rahbar MH, Bhutta ZA et al. (2006) Child's gender and household food insecurity are associated with stunting among young Pakistani children residing in urban squatter settlements. Food Nutr Bull 27, 114-127.

11. Hackett M, Melgar-Quinonez H \& Alvarez MC (2009) Household food insecurity associated with stunting and underweight among preschool children in Antioquia, Colombia. Rev Panam Salud Publica 25, 506-510.

12. Isanaka S, Mora-Plazas M, Lopez-Arana S et al. (2007) Food insecurity is highly prevalent and predicts underweight but not overweight in adults and school children from Bogota, Colombia. J Nutr 137, 2747-2755.

13. Mukhopadhyay DK \& Biswas AB (2011) Food security and anthropometric failure among tribal children in Bankura, West Bengal. Indian Pediatr 48, 311-314.

14. Psaki S, Bhutta Z, Ahmed T et al. (2012) Household food access and child malnutrition: results from the eight-country MAL-ED study. Popul Health Metr 10, 24.

15. Saha KK, Frongillo EA, Alam DS et al. (2009) Household food security is associated with growth of infants and young children in rural Bangladesh. Public Health Nutr 12, 1556-1562.

16. Kac G, Schlussel MM, Perez-Escamilla R et al. (2012) Household food insecurity is not associated with BMI for age or weight for height among Brazilian children aged 0-60 months. Plos One 7, e45747.

17. Pasricha S-R \& Biggs B-A (2010) Undernutrition among children in South and South East Asia. J Paediatr Child Health 46, 497-503.

18. Ministry of Health and Population, New ERA MII \& ICF International Inc. (2012) Nepal Demographic and Health Survey. Kathmandu and Calverton, MD: Ministry of Health and Population, New ERA and ICF International Inc.

19. Joshi NP, Maharjan KL \& Piya L (2010) Poverty and food insecurity in Nepal: a review. J Int Dev Coop 16, 1-19.

20. Food and Agriculture Organization of the United Nations/ World Food Programme (2007) Special Report on the Food Security Assessment Mission to Nepal. Rome: FAO.

21. United Nations Development Programme (2008) Human Development Indices: A Statistical Update. New York: UNDP.

22. Osei A, Pandey P, Spiro D et al. (2010) Household food insecurity and nutritional status of children aged 6 to 23 months in Kailali District of Nepal. Food Nutr Bull 31, 483-494.

23. World Health Organization (1995) Physical Status: The Use of and Interpretation of Anthropometry. Report of a WHO Expert Committee. WHO Tecthnical Report Series no. 854. Geneva: WHO.

24. World Health Organization (2010) The WHO child growth standards. http://www.who.int/childgrowth/standards/en/ (accessed November 2012).

25. Coates J, Swindale A \& Bilinsky P (2007) Household Food Insecurity Access Scale (HFIAS) for Measurement of Food Access: Indicator Guide. Washington, DC: Food and Nutrition Technical Assistance Project, Academy for Educational Development.

26. Coates J, Frongillo EA, Rogers BL et al. (2006) Commonalities in the experience of household food insecurity across cultures: what are measures missing? J Nutr 136, issue 5, 1438S-1448S. 
27. UNICEF (1998) The State of the World's Children 1998: a UNICEF report. Malnutrition: causes, consequences, and solutions. Nutr Rev 56, 115-123.

28. Olusanya BO, Wirz SL \& Renner JK (2010) Prevalence, pattern and risk factors for undernutrition in early infancy using the WHO Multicentre Growth Reference: a communitybased study. Paediatr Perinat Epidemiol 24, 572-583.

29. Adams EJ, Grummer-Strawn L \& Chavez G (2003) Food insecurity is associated with increased risk of obesity in California women. J Nutr 133, 1070-1074.

30. Townsend MS, Peerson J, Love B et al. (2001) Food insecurity is positively related to overweight in women. $J$ Nutr 131, 1738-1745.
31. Kac G, Velasquez-Melendez G, Schlussel MM et al. (2012) Severe food insecurity is associated with obesity among Brazilian adolescent females. Public Health Nutr 15, $1854-1860$.

32. Shariff ZM \& Khor GL (2005) Obesity and household food insecurity: evidence from a sample of rural households in Malaysia. Eur J Clin Nutr 59, 1049-1058.

33. Velasquez-Melendez G, SchlUssel MM, Brito AS et al. (2011) Mild but not light or severe food insecurity is associated with obesity among Brazilian women. J Nutr 141, 898-902.

34. Knueppel D, Demment M \& Kaiser L (2010) Validation of the household food insecurity access scale in rural Tanzania. Public Health Nutr 13, 360-367. 